\title{
PROJECTION METHODS FOR ECONOMIES WITH HETEROGENEOUS AGENTS
}

\author{
Radim Boháček \\ Michal Kejak
}
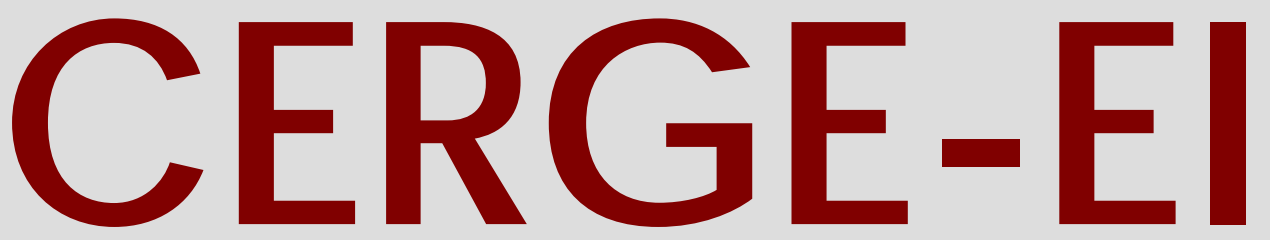

Charles University CenterforEconomic Research and Graduate Education Academy of Sciences of the Czech Republic Ec onomic Institute 


\section{Working Paper Series $\quad 258$ (ISSN 1211-3298)}

\section{Projection Methods \\ for Economies with Heterogeneous Agents}

Radim Boháček

Michal Kejak

CERGE-EI

Prague, May 2005 
ISBN 80-7343-052-5 (Univerzita Karlova v Praze, CERGE)

ISBN 80-7344-041-5 (Národohospodářský ústav AV ČR, Praha) 


\title{
Projection Methods for Economies with Heterogeneous Agents*
}

\author{
Radim Boháček and Michal Kejak ${ }^{\dagger}$
}

\begin{abstract}
In this paper we develop a general methodology for solving models with heterogeneous agents by projection methods. Our approach is solely based on the functional forms of agents' optimal policy rules and on a functional condition on the endogenous stationary distribution. Solving simultaneously the optimal policy rules and the distribution, this paper provides a new methodology for computing equilibria in which the distribution of wealth and income is a part of a social planner's optimization problem. We do not impose any additional restrictions or assumptions on the equilibrium allocations. Compared to other computational methods, it does not suffer from the curse of dimensionality and provides an efficient tool for computing models of economies with a continuum of heterogeneous agents with several endogenous and exogenous state variables. We illustrate the algorithm on a standard model with uninsurable idiosyncratic risk from labor income. The approximate solution is highly accurate, especially for the distribution function. This method can be used to compute equilibria in economies with heterogeneous agents in which the distribution of wealth and income is a part of a government's optimization problem.
\end{abstract}

*This version: June 2003

†Contact: CERGE-EI, Politickych veznu 7, 11121 Prague 1, Czech Republic. Email: radim.bohacek@cerge-ei.cz, michal.kejak@cerge-ei.cz. 


\begin{abstract}
Abstrakt
V této práci navrhujeme obecnou metodologii pro řešení modelǔ s heterogenními agenty projekční metodou. Náš prrístup je založen na optimálních rozhodovacích pravidlech agentǔ vyjádřených výlučně ve formě funkcionálu a na fukcionální podmínce pro endogenní stacionární rozložení. Tím, že řešíme současně optimální rozhodovací pravidla a rozložení, navrhujeme zde novou metodologii, která umožňuje výpočet rovnovážných řešení problémǔ, ve kterých je rozložení bohatství a př́ijmu součástí optimalizačního problému sociálního plánovače. Přitom na rovnovážnou alokaci nejsou kladena žádná dodatečná omezení ani předpoklady. Ve srovnání s jinými výpočetními metodami je naše metoda odolnější vǔči problému dimenzionality (curse of dimensionality) a poskytuje tak účinný nástroj pro pro výpočet modelǔ ekonomik s kontinuem heterogenních agentǔ s několika endogenními a exogenními stavovými proměnnými. Algoritmus je ilustrován na standardním modelu s nepojistitelným idiosynkratickým rizikem v pracovním př́ijmu. Aproximované řešení zvláště pro funkci rozložení je vysoce přesné. Tato metoda mǔže být také užita pro výpočet rovnovážných řešení $\mathrm{v}$ ekonomikách $\mathrm{s}$ heterogenními agenty, ve kterých je rozložení bohatství a příjmu součástí vládního optimalizačního problému.
\end{abstract}

JEL Classification: C61, C68, D30, D58 


\section{Introduction}

Models with heterogeneous agents have become a standard part of modern macroeconomic theory. Recent developments in computer technology have allowed economists to formulate and numerically simulate economies in which agents differ in their levels of accumulated assets, labor productivity, skills, education, age, or preferences. These more realistic models are particularly important for analyzing the welfare implications of government policies and their effects on wealth and income distribution.

In economies with endogenous distribution of heterogeneous agents, agents differ in their endogenous individual state variable and in a realization of some uninsurable idiosyncratic shock. The key feature that distinguishes these models from the representativeagent economies is that the set of possible trades available for agents is restricted. As the agents cannot write contracts contingent on their idiosyncratic shocks and, as in some cases, cannot hold negative quantities of any asset, the standard aggregation results do not hold. In general, the equilibrium prices and allocations depend on the distribution of agents in the economy.

Computing equilibria in economies with heterogeneous agents have proven to be an extremely difficult task. The problem is that distribution of agents across their individual state becomes a state of the economy. In making decisions, agents have to forecast future prices, and the law of motion of these prices depend on the law of motion of the distribution of agents. Solving for a stationary recursive equilibrium requires finding a fixed point in the space of functions from a set of measures into itself. The existing computational methods are usually limited to discretization of the state space. These methods suffer from the curse of dimensionality: simulating models with more than one endogenous state variable is extremely burdensome and becomes quickly impossible as the number of variables grows. Also, the usual quadratic-approximation methods cannot be used because constraints are often binding.

Finally, solving for out-of-steady-state allocations with these methods is virtually impossible without knowing the law of motion for the whole economy, namely for the distribution of the individual state variables. The practice has been to reduce the dimensionality of the problem by arbitrarily preventing the distribution of agents from affecting 
relative prices, transition between two steady states, and assuming bounded rationality by using only partial information (usually moments of the distribution). Rios-Rull (1997) provides a great survey of these methods and related computational issues.

In this paper, we offer a computational method that overcomes most of the problems stated above and promises a way how to address the issues in the previous paragraph. To do so we develop a general structure of equilibria in economies with a continuum of heterogenous agents which can be expressed in the form of three classes of equilibrium conditions: the first order conditions and the laws of motion; the stationarity condition on the distribution function; and the aggregate conditions. These conditions form a system of functional equations in the unknown policy and distribution functions which we solve numerically using the projection methods. We look for a polynomial approximation of the policy and distribution functions which solve these functional equations. The general formulation of the equilibrium conditions enables us to develop a general algorithm for the three most common projection methods (the collocation, Galerkin, and the least squares methods) intended for models with a representative agent. The implemented algorithm demonstrates a very good accuracy of the obtained approximate solutions, especially in preserving the shape of the cumulative distribution function.

Our method provides an efficient tool for computing models of economies with a continuum of heterogeneous agents with several endogenous and exogenous state variables. As in the traditional use of the projection method, it exploits the functional form of agents' policy rules and adds a functional condition for the distribution function that characterizes the equilibrium allocations. It should be emphasized that our approach does not use any additional restrictions or assumptions on the equilibrium allocations but is strictly derived from the first order and envelope conditions and from the stationarity of the endogenous distribution in the steady state.

We illustrate the projection method for heterogeneous agents on a standard model of an economy with uninsurable idiosyncratic risk from labor income. In the economy, agents are distinguished by their level of accumulated assets and labor income productivity shock. We simulate a stationary recursive competitive equilibrium in which the endogenous distribution of agents over their individual states is stationary and the aggregate levels and factor prices are constant. This model has been the foundation of 
important papers by Aiyagari (1994), Huggett (1993), Huggett (1997), Ventura (1999), as well as the main model of the survey in Rios-Rull (1995). Many life-cycle studies, like that of Huggett and Ventura (1999), are also based on this specification.

In our paper we draw extensively on the projection methods developed for computational economics with representative agent by Judd $(1992)^{1}$. Various approximation techniques and alternative approaches are described in Judd (1998). Judd, Kubler, and Schmedders (2000) applied projection and perturbation methods to an asset pricing model with incomplete markets and several types of agents. Their model does not, however, consider a stationary equilibrium with endogenous distribution of resources in the economy.

Our methodology can be used in numerical simulation of richer and more realistic economic environments needed for assessing the welfare and distributional implications of government policies. For example, it can be extended to include asymmetric information (as in Phelan and Townsend (1991) or Atkeson and Lucas (1995)), equilibrium search (Alvarez and Veracierto (1999)), financial intermediation and occupational choice (Bohacek (2002)), monetary policies (Lucas (1980)), unemployment (Hansen and Imrohoroglu (1992)), or politico-economic equilibria (Krusell, Quadrini, and Rios-Rull (1997)).

The paper is organized as follows. Section 2 describes an economy with heterogeneous agents and uninsurable idiosyncratic risk in labor income. Section 3 develops a general structure of equilibria in such economies with heterogenous agents. Section 4 describes a general algorithm for the projection methods. Section 5 demonstrates the algorithm on the economy specified in section 2. Section 6 presents and compares the solutions from three standard projection methods: the collocation, Galerkin, and the least squares methods. Section 6 concludes.

\footnotetext{
${ }^{1}$ See also Kejak (2000) for an application of the projection method in endogenous growth theory using a toolkit PROJEC in GAUSS.
} 


\section{The Economy}

The economy is populated by a continuum of infinitely lived agents on a unit interval. Each agent has preferences over consumption given by a utility function

$$
E\left[\sum_{t=0}^{\infty} \beta^{t} u\left(c_{t}\right)\right],
$$

where $\beta \in(0,1)$ and $u: \mathbb{R}_{+} \rightarrow \mathbb{R}$ is bounded, strictly increasing and strictly concave, and twice differentiable continuous function. We assume that the utility function satisfies the Inada conditions.

In each period, each agent receives a stochastic labor productivity shock $z \in Z=[\underline{z}, \bar{z}]$ measured in efficiency units. The labor productivity shock is independent across agents and follows a first-order Markov process with a transition function $Q$. We assume that $Q$ is monotone, satisfies the Feller property and $Q(z, \cdot)>0$ for all $z \in Z$. Thus there is uncertainty at the individual level but there is no uncertainty over the aggregate labor supply.

All agents are initially endowed with a nonnegative stock of capital. In each period, each agent supplies his realized labor endowment and accumulated capital stock $k$ to competitive firms operating a constant returns to scale production technologies. We restrict the accumulated capital to be nonnegative, $k \in B=[\underline{k}, \infty)$ where $\underline{k}=0$. Finally, the capital stock depreciates at a rate $\delta \in(0,1)$.

As usual, we consider a competitive equilibrium with a representative firm that uses the aggregate capital stock $K$ and the aggregate effective labor $L$ in a production technology $F(K, L)=A K^{\alpha} L^{1-\alpha}$. Profit maximization implies the following factor prices

$$
r=F_{K}(K, L) \text { and } w=F_{L}(K, L)
$$

Thus in each period, an agent inelastically supplies his labor endowment at wage $w$, rents capital stock at interest rate $r$, and maximizes his or her utility by choosing a level of capital stock for the next period.

We will model the economy in a stationary recursive competitive equilibrium. Such an equilibrium exhibits constant factor prices, constant levels of aggregate variables and a stationary distribution of agents over their individual states. An agent's individual state 
is a pair $(k, z) \in B \times Z$ denoting his or her accumulated stock of capital and the realized labor productivity shock, respectively. Taking the factor prices $(w, r)$ as given, an agent $(k, z)$ solves the following dynamic programming problem

$$
v(k, z)=\max _{c, k^{\prime}}\left\{u(c)+\beta \int v\left(k^{\prime}, z^{\prime}\right) Q\left(z, d z^{\prime}\right)\right\}
$$

subject to a budget constraint

$$
c+k^{\prime} \leq w z+r k+(1-\delta) k,
$$

and

$$
c \geq 0, k^{\prime} \geq 0 \text {. }
$$

A probability measure $\lambda$ defined on subsets of the state space is a natural way of describing the heterogeneity of the agents in their individual state $(k, z)$. Let $(B \times$ $Z, \mathcal{B}(B \times Z), \lambda)$ be a probability space, where $\mathcal{B}(B \times Z)$ is the Borel $\sigma$-algebra on $B \times Z$. We interpret $\lambda$ as a probability measure describing the fractions of agents with the same individual state.

The policy function for next-period capital $k^{\prime}(k, z)$ and the Markov process for the productivity shock generate a law of motion

$$
\lambda^{\prime}\left(B^{\prime}, Z^{\prime}\right)=\iint_{\left\{(k, z) \in B \times Z: k^{\prime}(k, z) \in B^{\prime}\right\}} Q\left(z, Z^{\prime}\right) \lambda(k, z) d k d z
$$

for all $B^{\prime}$ and $Z^{\prime}$. According to this law of motion, the fraction of agents that will begin next period with capital stock in the set $B^{\prime}$ and a productivity shock in the set $Z^{\prime}$ is given by all those agents that transit from their current shock $z \in Z$ to a shock in $Z^{\prime}$ and whose optimal decision for capital accumulation belongs to $B^{\prime}$.

Definition 1 A stationary recursive competitive equilibrium consists of constant factor prices $(r, w)$, a value function $v(k, z)$, policy functions $c(k, z)$ and $k^{\prime}(k, z)$, a probability measure $\lambda$, and aggregate levels $(K, L)$, such that

1. the factor prices $(r, w)$ solve equation (1),

2. at prices $(r, w)$, the policy functions $c(k, z)$ and $k^{\prime}(k, z)$ solve the value function $v(k, z)$ for each $(k, z) \in B \times Z$, 
3. the probability measure $\lambda$ is time invariant,

4. the capital and labor markets clear,

$$
\begin{aligned}
K & =\iint k^{\prime}(k, z) \lambda(k, z) d k d z, \\
L & =\iint z \lambda(k, z) d k d z,
\end{aligned}
$$

5. and the aggregate feasibility constraint holds at equality,

$$
\iint\left\{c(k, z)+k^{\prime}(k, z)\right\} \lambda(k, z) d k d z=F(K, L)+(1-\delta) K .
$$

Note that the aggregate feasibility constraint is implied from the other market clearing conditions by the Walras' law. The proof of existence and uniqueness of the equilibrium is now standard and the reader is referred to Stokey, Lucas, and Prescott (1989) for details.

\section{Projection Methods for Models with Heterogenous Agents}

In this section we develop a general methodology for applying projections methods to stationary equilibria in economies with a continuum of heterogenous agents. The whole structure is based on the following three classes of equilibrium conditions:

1. The first order conditions and the laws of motion;

2. Stationarity condition on the distribution function; and

3. Aggregate conditions.

Let $x \in \mathbb{R}^{n}$ be a vector of endogenous state variables, $s \in \mathbb{R}^{p}$ be a vector of exogenous shocks, $q$ be a vector of policy functions $q: \mathbb{R}^{n} \times \mathbb{R}^{p} \longrightarrow \mathbb{R}^{m}$, and $\mu$ be a joint distribution function of state variables $\mu: \mathbb{R}^{n} \times \mathbb{R}^{p} \longrightarrow[0,1]$. Let $X=\mathbb{R}^{n}$ stands for a vector of values of the endogenous economy-wide state variables. Because we consider no economy-wide shocks, there are no exogenous economy-wide state variables and prices are only functions of the endogenous economy-wide state variables. Now we can specify each class of the equilibrium conditions in the following way: 
The first order conditions and the laws of motion This class of conditions contains the first order conditions and the laws of motion for individual endogenous state variables after the substitution of envelope conditions, individual budget constraints, and equilibrium prices. These conditions form a system of $m$ functional and $n$ difference equations

$$
\begin{aligned}
\mathcal{E}\left\{f\left(q(x, s), x, s, X, q\left(x^{\prime}, s^{\prime}\right), x^{\prime}, s^{\prime}\right)\right\} & =\mathbf{0}, \\
d(q(x, s), x, s, X) & =x^{\prime},
\end{aligned}
$$

where $f$ is a $m$-vector function with $f_{i}: \mathbb{R}^{m} \times \mathbb{R}^{n} \times \mathbb{R}^{p} \times \mathbb{R}^{n} \times \mathbb{R}^{m} \times \mathbb{R}^{n} \times \mathbb{R}^{p} \longrightarrow \mathbb{R}$ for $i=1, \ldots, m$. The laws of motion for the endogenous state variables are specified by a $n$ dimensional vector function, $d$, where $d_{i}: \mathbb{R}^{m} \times \mathbb{R}^{n} \times \mathbb{R}^{p} \times \mathbb{R}^{n} \longrightarrow \mathbb{R}$ for $i=1, \ldots, n$. The expectational operator $\mathcal{E}$, with implicitly defined transition functions for the exogenous shocks, is conditional on an agent's individual state, $(x, s)$, and prices.

Stationarity condition on the distribution function The second class of conditions forms one functional equation for the stationarity condition on the joint distribution function of the state variables:

$$
\mathcal{A}\left\{g\left(\mu(x, s), \mu\left(x^{\prime}, s^{\prime}\right)\right) \mid e\left(q(x, s), x, s, X, x^{\prime}\right)=\mathbf{0}\right\}=0
$$

where $g:[0,1] \times[0,1] \longrightarrow \mathbb{R}$, and $\mathcal{A}$ is an operator on the space of continuous functions defined on measurable spaces of endogenous and exogenous state variables, $\mathbb{R}^{n}$ and $\mathbb{R}^{p}$, respectively. The function $e$ is defined as $e: \mathbb{R}^{m} \times \mathbb{R}^{n} \times \mathbb{R}^{p} \times \mathbb{R}^{n} \times \mathbb{R}^{n} \longrightarrow \mathbb{R}^{n} \times \mathbb{R}^{p}$, specifying additional conditions expressed in the implicit form related to the operator $\mathcal{A}$.

To illustrate the stationarity condition, consider the model specified in the previous section with only one endogenous and one exogenous individual state variables, $k \in B$, $z \in Z$, respectively. Then according to equation (5), the stationarity condition (10) can be expressed as

$$
\lambda\left(B^{\prime}, Z^{\prime}\right)=\iint_{\left\{(k, z) \in B \times Z: k^{\prime}=(1-\delta+r(K)) k+w(K) z-c(k, z) ; k^{\prime} \in B^{\prime}\right\}} Q\left(z, Z^{\prime}\right) \lambda(k, z) d k d z .
$$

The implicit condition $e$ - only 1-dimensional here - defines a set of all pairs $(k, z) \in B \times Z$, i.e. the domain of integration, that implies next period states $\left(k^{\prime}, z^{\prime}\right) \in B^{\prime} \times Z^{\prime}$. 
Aggregate conditions The last set of $l>n+1$ conditions is composed of $n$ aggregate conditions on endogenous state variables, $l-(n+1)$ market clearing conditions on additional endogenous variables $h$, and of one condition on the probability distribution, respectively,

$$
\begin{aligned}
\mathcal{I}\left\{x^{\prime}, \mu(x, s)\right\} & =X, \\
\mathcal{I}\{h, \mu(x, s)\} & =H, \\
\mathcal{I}\{1, \mu(x, s)\} & =1,
\end{aligned}
$$

where $\mathcal{I}$ stands for integration. The aggregate conditions (11)-(12) can be illustrated in our model by using equations (6)-(7). The condition (13) captures the condition on the probability density function. For our modelled economy,

$$
\begin{aligned}
K & =\int_{Z} \int_{B} k^{\prime}(k, z) \lambda(k, z) d k d z \\
L & =\int_{Z} \int_{B} z \lambda(k, z) d k d z \\
1 & =\int_{Z} \int_{B} \lambda(k, z) d k d z
\end{aligned}
$$

\section{Algorithm for Projection Methods}

In this section we describe a general algorithm for the projection methods for models with heterogenous agents. The algorithm is based on the following steps:

Step 1 Define operators $\mathcal{N}$ composed of functional equations expressing the first two classes of equilibrium conditions (8)-(10),

$$
\left(\begin{array}{c}
\mathcal{N}_{1}(q) \\
\mathcal{N}_{2}(q) \\
\vdots \\
\mathcal{N}_{m}(q) \\
\mathcal{N}_{m+1}(q, \mu)
\end{array}\right)=\left(\begin{array}{c}
0 \\
0 \\
\vdots \\
0 \\
0
\end{array}\right),
$$

where the unknown functions are $m$ policy functions $q_{i}$ and the distribution function $\mu$. The third class, the aggregate conditions (11)-(12), are not functional equations and thus 
are not part of the operator equations. They will be included into the projection algorithm as a set of special conditions later.

Step 2 The solution of the above functional equations, a $m$-dimensional policy function $q$ and a joint distribution function $\mu$, are the zeros of the operators $\mathcal{N}_{i}$. Standard approximation methods transform this infinite-dimensional problem into a finite-dimensional one. To do this we first choose a base of multidimensional approximation polynomials ${ }^{2}$, $\left\{\Phi_{i}\right\}_{i=1}^{\infty}$, where $\Phi_{i}: Y \subseteq \mathbb{R}^{n} \times \mathbb{R}^{p} \longrightarrow \mathbb{R}$, and approximate the unknown policy and distribution functions by

$$
\begin{aligned}
& \hat{q}_{i}\left(x, s ; a^{i}\right) \equiv \sum_{j=1}^{N} a_{j}^{i} \Phi_{j}(x, s) \quad \text { for } i=1, \ldots, m, \\
& \hat{\mu}\left(x, s ; a^{m+1}\right) \equiv \sum_{j=1}^{M} a_{j}^{m+1} \Phi_{j}(x, s),
\end{aligned}
$$

where $N$ and $M$ are the number of polynomial terms ${ }^{3}$ used in the approximation of the policy functions and the distribution function, respectively. Part of this step is also the specification of the domain of approximation, $Y$.

Step 3 In general, our operators $\mathcal{N}_{i}, i=1, \ldots, m+1$, are integral operators and we use standard quadrature techniques ${ }^{4}$ to approximate them by $\hat{\mathcal{N}}_{i}$. As the aggregate conditions (11)-(13) contain integrals we apply the quadrature techniques for them too. The quadrature techniques employed in this paper will be briefly discussed in the next section.

\footnotetext{
${ }^{2}$ The multidimensional polynomial base, $\left\{\Phi_{i}\right\}_{i=1}^{\infty}$, is formed by the tensor products of univariate polynomials, $\left\{\phi_{k}\right\}_{k=0}^{\infty}$, i.e. $\Phi_{i}(x, s)=\left\{\prod_{j=1}^{n} \prod_{l=1}^{p} \phi_{k_{j}}\left(x_{j}\right) \phi_{k_{l}}\left(s_{l}\right) \mid k_{j}, k_{l}=0,1,2, \ldots\right\}$, where $\left(k_{1}, \ldots, k_{j}, \ldots, k_{n}\right)$ and $\left(k_{1}, \ldots, k_{l}, \ldots, k_{s}\right)$ form vectors of the degrees of polynomial multidimensional approximation in the endogenous and the exogenous state variables, respectively. Each element of the vector represents the degree of approximation in a particular dimension.

${ }^{3}$ For higher dimensional problems it is more convenient to use a subset of tensor product, e.g. a complete polynomial base.

${ }^{4}$ See Judd (1998) for a survey on the approximation techniques for integrals.
} 
Step 4 Using the approximation specifications of the policy and distribution functions and of the integral operators, the residual functions can be defined as

$$
\left(\begin{array}{c}
R_{1}(x, s ; \mathbf{a}) \\
R_{2}(x, s ; \mathbf{a}) \\
\vdots \\
R_{m}(x, s ; \mathbf{a}) \\
R_{m+1}(x, s ; \tilde{\mathbf{a}})
\end{array}\right) \equiv\left(\begin{array}{c}
\hat{\mathcal{N}}_{1}(\hat{q}(x, s ; \mathbf{a})) \\
\hat{\mathcal{N}}_{2}(\hat{q}(x, s ; \mathbf{a})) \\
\vdots \\
\hat{\mathcal{N}}_{m}(\hat{q}(x, s ; \mathbf{a})) \\
\hat{\mathcal{N}}_{m+1}\left(\hat{q}(x, s ; \mathbf{a}), \hat{\mu}\left(x, s ; a^{m+1}\right)\right)
\end{array}\right)
$$

for all $(x, s) \in Y$ and for vectors of approximation parameters $a^{i} \in \mathbb{R}^{N}, i=1, \ldots, m$, and $a^{m+1} \in \mathbb{R}^{M}$ where $\mathbf{a}=\left(a^{1}, a^{2}, \ldots, a^{m}\right)^{T}$ and $\tilde{\mathbf{a}} \equiv\left(\mathbf{a}^{T}, a^{m+1}\right)^{T}$.

We need to guess values for the economy-wide endogenous state, $X$, and non-state, $H$, variables necessary for the calculation of factor prices. Thus the content of this step is, given a parameter guess $\tilde{\mathbf{a}}$ and the aggregate guesses $X$ and $H$, to calculate approximations of $\hat{q}_{i}, i=1, \ldots, m, \hat{\mu}$ and the residual functions $R_{i}$, using formulas (15)-(16) and (17), respectively.

Step 5 Ideally, the residual functions should be uniformly equal to zero. In practical situations, however, this is not achievable and we limit the problem to a finite number of conditions, the so called projections, whose satisfaction will guarantee a reasonably good approximation. The aim of this step is - for the parameter guess $\tilde{\mathbf{a}}$ and the guesses for $X$ and $H$ - to calculate the projections of the residual function.

There are many possibilities how to define the projections ${ }^{5}$, however, for the purpose of this paper we limit our attention to three basic projection methods: the collocation method, the Galerkin method, and the least squares projection method.

Collocation Method The idea behind the collocation method is to assign the value of the residual function to zero only at a set of prespecified points. We follow the well known results of the approximation theory and use a set of zeros associated with the chosen polynomial base. Let $\left\{y_{k}^{0} \equiv\left(x_{k}^{0}, s_{k}^{0}\right)\right\}_{k=1}^{P}$ be composed of the "zeros" of the $P$ th member of the multidimensional polynomial ${ }^{6}$ base and let $P$ stand for the number of

\footnotetext{
${ }^{5}$ For an excellent survey and description of these methods see Chapter 11 in Judd (1998).

${ }^{6}$ The multidimensional "zeros" are composed of the zeros of univariate polynomials $\phi_{i}$.
} 
polynomial terms used in the approximation of a function. If the basis elements are orthogonal with respect to the inner product the collocation method is called orthogonal.

Since the chosen degree of approximation of the policy functions was $N$, we use $N$ zeros of the $N$ th base polynomial to generate $N$ projections. Similarly, we produce $M$ projections for the distribution function. Thus, the original functional equations problem is transformed into a $m \times N+M$ nonlinear algebraic equations in $m \times N+M$ unknown approximation parameters

$$
\left(\begin{array}{c}
\mathbf{R}_{1}\left(\mathbf{x}_{N}^{0}, \mathbf{s}_{N}^{0} ; \mathbf{a}\right) \\
\mathbf{R}_{2}\left(\mathbf{x}_{N}^{0}, \mathbf{s}_{N}^{0} ; \mathbf{a}\right) \\
\vdots \\
\mathbf{R}_{m}\left(\mathbf{x}_{N}^{0}, \mathbf{s}_{N}^{0} ; \mathbf{a}\right) \\
\mathbf{R}_{m+1}\left(\mathbf{x}_{M}^{0}, \mathbf{s}_{M}^{0} ; \tilde{\mathbf{a}}\right)
\end{array}\right) \equiv\left(\begin{array}{c}
\mathbf{0} \\
\mathbf{0} \\
\vdots \\
\mathbf{0} \\
\mathbf{0}
\end{array}\right)
$$

where

$$
\mathbf{R}_{i}\left(\mathbf{x}_{N}^{0}, \mathbf{s}_{N}^{0} ; \mathbf{a}\right) \equiv\left(R_{i}\left(x_{1}^{0}, s_{1}^{0} ; \mathbf{a}\right), R_{i}\left(x_{2}^{0}, s_{2}^{0} ; \mathbf{a}\right), \ldots, R_{i}\left(x_{N}^{0}, s_{N}^{0} ; \mathbf{a}\right)\right)^{T}
$$

for $i=1, \ldots, m$, and

$$
\mathbf{R}_{m+1}\left(\mathbf{x}_{M}^{0}, \mathbf{s}_{M}^{0} ; \tilde{\mathbf{a}}\right) \equiv\left(R_{m+1}\left(x_{1}^{0}, s_{1}^{0} ; \tilde{\mathbf{a}}\right), R_{m+1}\left(x_{2}^{0}, s_{2}^{0} ; \tilde{\mathbf{a}}\right), \ldots, R_{m+1}\left(x_{M}^{0}, s_{M}^{0} ; \tilde{\mathbf{a}}\right)\right)^{T},
$$

together with $\mathbf{x}_{P}^{0} \equiv\left(x_{1}^{0}, x_{2}^{0}, \ldots, x_{P}^{0}\right)^{T}$ and $\mathbf{s}_{P}^{0} \equiv\left(s_{1}^{0}, s_{2}^{0}, \ldots, s_{P}^{0}\right)^{T}$.

Galerkin Method The Galerkin method constructs the projections using the inner product of the residual functions (17) and particular elements of the polynomial base $\left\{\Phi_{i}\right\}_{i=1}^{\infty}$. If the inner product of functions $f$ and $g$ on the functional space is defined by $\langle f, g\rangle \equiv \int f(y) g(y) w(y) d y$, with a weighting function $w$, then we obtain the following system of nonlinear algebraic equations,

$$
\left(\begin{array}{c}
\mathbf{P}_{1}(\mathbf{a}) \\
\mathbf{P}_{2}(\mathbf{a}) \\
\vdots \\
\mathbf{P}_{m}(\mathbf{a}) \\
\mathbf{P}_{m+1}(\tilde{\mathbf{a}})
\end{array}\right) \equiv\left(\begin{array}{c}
\mathbf{0} \\
\mathbf{0} \\
\vdots \\
\mathbf{0} \\
\mathbf{0}
\end{array}\right)
$$


where

$$
\mathbf{P}_{i}(\mathbf{a}) \equiv\left(\left\langle R_{i}(x, s ; \mathbf{a}), \Phi_{1}(x, s)\right\rangle,\left\langle R_{i}(x, s ; \mathbf{a}), \Phi_{2}(x, s)\right\rangle, \ldots,\left\langle R_{i}(x, s ; \mathbf{a}), \Phi_{N}(x, s)\right\rangle\right)^{T}
$$

for $i=1, \ldots, m$, and

$$
\mathbf{P}_{m+1}(\tilde{\mathbf{a}}) \equiv\left(\left\langle R_{m+1}(x, s ; \tilde{\mathbf{a}}), \Phi_{1}(x, s)\right\rangle, \ldots,\left\langle R_{m+1}(x, s ; \tilde{\mathbf{a}}), \Phi_{M}(x, s)\right\rangle\right)^{T}
$$

The computation of the inner product includes integration for which we use the usual quadrature techniques. Again, the outcome of $m \times N+M$ projections are $m \times N+M$ nonlinear algebraic equations in $m \times N+M$ unknown approximation parameters.

Least Squares Projection Method The least squares projection method is slightly different from the above two projection approaches as it looks for parameters ã that minimize the sum of weighted squared residuals,

$$
\min _{\tilde{\mathbf{a}} \in \mathbb{R}^{m \times N+M}} \sum_{i=1}^{m}\left\langle R_{i}(x, s ; \mathbf{a}), R_{i}(x, s ; \mathbf{a})\right\rangle+\left\langle R_{m+1}(x, s ; \tilde{\mathbf{a}}), R_{m+1}(x, s ; \tilde{\mathbf{a}})\right\rangle .
$$

Up to now we omitted in our discussion a set of the aggregation conditions in (11)(13). It is clear that these are the additional conditions which must be satisfied in the stationary recursive equilibrium. However, this addition leads to an overidentified system with $m \times N+M+l$ nonlinear equations in $m \times N+M$ unknown parameters. Though the overidentified system can be handled by the least square method, it causes a problem for the collocation and the Galerkin methods. In principle, there are two ways how to proceed: We either overwrite a subset of the $l$ projection conditions from (18) or (19) by the additional conditions and solve a regular nonlinear equation problem. Or we solve the original problem as an overidentified system using the nonlinear least squares method.

Step 6 In this step we calculate the new values of the economy-wide endogenous state and non-state variables according to the aggregation conditions (11)-(12). 
Step 7 We iterate on steps 4-6 and look for a parameter value ã and levels $X$ and $H$ which set all the projections equal to zero. We update the guess for the economy-wide endogenous states and non-states by a simple linear combination of the previous guess and the aggregate values calculated in step 6 .

As the collocation and Galerkin methods represent standard nonlinear equation problems we can use any of the existing methods to solve the problem of finding the appropriate parameter values $\tilde{\mathbf{a}}$. One of the most common method is the Newton method ${ }^{7}$. Since the least squares projection method sets up an optimization problem we can use standard methods of numerical optimization, e.g. the Gauss-Newton or the Levenberg-Marquardt methods. Again, the discussion of these methods is not the aim of our paper.

\section{Approximate Solution by Projection Methods}

In this section we illustrate the projection methods by applying the general algorithm developed in the previous section to our model with a continuum of infinitely-lived heterogenous agents. For the sake of simplicity we will consider here a version of the model with discrete shocks. Of course, the same approach can be used in a more general case with continuous shocks.

The idiosyncratic productivity shock $z$ takes on values in a finite set of real numbers, $z \in Z=\left\{z_{1}, z_{2}, \ldots, z_{J}\right\}$ and $J>1$. Let $Q\left(z, z^{\prime}\right)=\operatorname{Prob}\left(z_{t+1}=z^{\prime} \mid z_{t}=z\right)$ be a first-order Markov chain. Then the recursive problem of each agent in (2)-(4) can be written as

$$
v(k, z)=\max _{k^{\prime}}\left\{u\left((1+r-\delta) k+w z-k^{\prime}\right)+\beta \sum_{z^{\prime} \in Z} v\left(k^{\prime}, z^{\prime}\right) Q\left(z, z^{\prime}\right)\right\} .
$$

The first order and the envelope conditions are

$$
u_{1}(c)=\beta \sum_{z^{\prime} \in Z} v_{1}\left(k^{\prime}, z^{\prime}\right) Q\left(z, z^{\prime}\right),
$$

and

$$
v_{1}(k, z)=u_{1}(c)(1+r-\delta),
$$

\footnotetext{
${ }^{7}$ See the Chapter 5 in Judd (1992).
} 
respectively. We now adapt the three classes of equilibrium conditions to the discrete version of the economy.

The first order conditions and the law of motion From the first order and the envelope conditions we derive the Euler equation. The law of motion is given by (3). Thus the first class of conditions (8) is composed of $m=1$ functional equation for the consumption policy function

$$
\beta \sum_{z^{\prime} \in Z} u_{1}\left(c\left(k^{\prime}, z^{\prime}\right)\right)(1+r(K)-\delta) Q\left(z, z^{\prime}\right)-u_{1}(c(k, z))=0
$$

and $n=1$ equation for the law of motion of the individual stock of physical capital,

$$
(1+r(K)-\delta) k+w(K) z-c(k, z)=k^{\prime}
$$

Because agents inelastically supply their labor productivity shock $z$, the aggregate labor supply is a fixed number, $L$. Thus, the equilibrium factor prices, $r(K)$ and $w(K)$, are functions of the economy-wide endogenous state $K$ only.

Due to the discrete character of shocks it is advantageous to assign to each level of shock a particular policy function and a distribution function. We consider these one dimensional functions of the individual state variable $k$ rather than working with twodimensional functions in $k$ and $z$ as in the original problem. ${ }^{8}$

For this specification, define a family of policy and distribution functions, $\left\{c_{i}(k), \lambda_{i}(k)\right\}_{i=1}^{J}$, for each shock value $z_{1}, z_{2}, \ldots, z_{J}$. We interpret the policy function $c_{i}$ as the consumption function of an agent who was hit by the shock level $z_{i}$. Analogously, the distribution function $\lambda_{i}$ is the distribution of agents with the shock $z_{i}$. Equations (24)-(25) can be rewritten as the following $2 \times J$ conditions

$$
\begin{aligned}
\beta \sum_{j=1}^{J} u_{1}\left(c_{j}\left(k^{\prime}\left(k, z_{i}\right)\right)\right)(1+r(K)-\delta) Q\left(z_{i}, z_{j}\right)-u_{1}\left(c_{i}(k)\right) & =0 \\
(1+r(K)-\delta) k+w(K) z_{i}-c_{i}(k) & =k^{\prime}\left(k, z_{i}\right)
\end{aligned}
$$

\footnotetext{
${ }^{8}$ Although the introduction of discrete shocks is used in the discretization methods in order to avoid the "curse of dimensionality", here we introduce the discrete shock model for the sake of simplicity of our explanation. The projection method approach, as we discussed above, can handle higher dimensional problems much more effectively than the traditional methods.
} 
for $i=1, \ldots, J$. After the substitution of the individual budget constraint (27) into the individual Euler equation (26), both associated with the same level of the idiosyncratic shock $z_{i}$, we obtain a functional equation for consumption policy functions $\mathcal{N}_{i}\left(c_{1}(k), \ldots, c_{J}(k)\right)$. Doing it for all shock values gives us a set of $J$ functional equations $\mathcal{N}_{i}(c(k)) \equiv \mathcal{N}_{i}\left(c_{1}(k), \ldots, c_{J}(k)\right)$, where $i=1, \ldots, J$.

Stationarity condition on the distribution function Having defined a family of distribution functions associated with each individual shock level, the single stationarity condition (10) is transformed to a set of $J$ stationarity conditions

$$
\lambda_{j}\left(k^{\prime}\right)=\sum_{i=1}^{J} \int_{\left\{k \in B: k^{\prime}=(1+r(K)-\delta) k+w(K) z_{i}-c_{i}(k)\right\}} Q\left(z_{i}, z_{j}\right) \lambda_{i}(k) d k
$$

where $j=1, \ldots, J$. Since there is a unique pair ${ }^{9}$ of current period states $\left(k, z_{i}\right)$ for each pair of next period states $\left(k^{\prime}, z_{j}\right)$ at given prices, the set of integration collapses into a point, $k=k\left(k^{\prime}\right) \in B$, and the integration disappears. A set of $J$ stationarity conditions is now

$$
\lambda_{j}\left(k^{\prime}\right)=\sum_{i=1}^{J} k\left(k^{\prime}\right) Q\left(z_{i}, z_{j}\right) \lambda_{i}\left(k\left(k^{\prime}\right)\right)
$$

and forms the second set of $J$ functional equations

$$
\mathcal{N}_{j+J}(c, \lambda) \equiv \mathcal{N}_{j+J}\left(c_{1}(k), \ldots, c_{J}(k), \lambda_{1}(k), \ldots, \lambda_{J}(k)\right)
$$

where $j=1, \ldots, J$.

Aggregate conditions Aggregate conditions (11)-(13) of the model with discrete shocks are given by

$$
K=\sum_{i=1}^{J} \int_{B} k^{\prime}\left(k, z_{i}\right) \lambda_{i}(k) d k
$$

\footnotetext{
${ }^{9}$ In this model there is only one solution $k$ of the implicit equation $(1+r(K)-\delta) k+w(K) z_{i}-c_{i}(k)-k^{\prime}=$ 0 for all $k^{\prime}, K, z_{i}, z_{j}$ and policy function $c_{i}$. To be aware that the solution depends on the policy function $c_{i}$ one might prefer to write $k=k\left(k^{\prime}, K, z_{i}, z_{j} ; c_{i}\right) \equiv k\left(k^{\prime}\right)$.
} 


$$
\begin{aligned}
L & =\sum_{i=1}^{J} \int_{B} z_{i} \lambda_{i}(k) d k \\
1 & =\sum_{i=1}^{J} \int_{B} \lambda_{i}(k) d k
\end{aligned}
$$

where the next period capital as a function of the current state, $k^{\prime}\left(k, z_{i}\right)$, is expressed in (27). Since there is no labor choice the aggregation condition (31) can be computed from the stationary distribution of shocks $\lim _{t \rightarrow \infty} Q^{t}$ and included directly into the model parameters instead of the equilibrium projection conditions.

Having specified the system of functional equations given by $\mathcal{N}$, the next step is to choose the polynomial base, the degrees of approximation, and the interval of approximation. We follow the best practice in the approximation theory and choose the orthogonal Chebyshev polynomial base ${ }^{10}\left\{T_{i}(x)\right\}_{i=0}^{\infty}$ defined for $x \in[-1,1]$. Let the interval of approximation be $[\underline{k}, \bar{k}]$ and the degree of approximation for the consumption policy functions, $c$, and the distribution function, $\lambda$, be $M \geq 2$ and $N \geq 2$, respectively. The linear transformation ${ }^{11} \xi:[\underline{k}, \bar{k}] \rightarrow[-1,1]$ is necessary if we want to use the Chebyshev polynomials on the proper domain. Then, we obtain

$$
\begin{array}{rlrl}
\hat{c}_{i}\left(k ; a^{i}\right) & \equiv \sum_{j=1}^{N} a_{j}^{i} \phi_{j}(k) & \text { for } i=1, \ldots, J, \\
\hat{\lambda}_{j}\left(k ; a^{j}\right) \equiv \sum_{l=1}^{M} a_{l}^{j} \phi_{l}(k), & \text { for } j=J+1, \ldots, 2 J,
\end{array}
$$

where $\phi_{i}(k) \equiv T_{i-1}(\xi(k))$.

Using the equations (26)-(27) and (29), the residual functions become

$$
\begin{aligned}
R_{i}(k ; \mathbf{a}) & =\beta \sum_{j=1}^{J} u_{1}\left(\hat{c}_{j}\left((1+r(K)-\delta) k+w(K) z_{i}-\hat{c}_{i}(k)\right)\right)(1+r(K)-\delta) Q\left(z_{i}, z_{j}\right) \\
& -u_{1}\left(\hat{c}_{i}(k)\right)=0, \quad \text { for } i=1, \ldots, J \\
R_{j+J}\left(k^{\prime} ; \tilde{\mathbf{a}}\right) & =\hat{\lambda}_{j}\left(k^{\prime}\right)-\sum_{i=1}^{J} k\left(k^{\prime}\right) Q\left(z_{i}, z_{j}\right) \hat{\lambda}_{i}\left(k\left(k^{\prime}\right)\right)
\end{aligned}
$$

\footnotetext{
${ }^{10}$ The details on Chebyshev polynomials can be found in Judd (1992), Judd (1998) or in any book on numerical mathematics.

${ }^{11}$ It is straightforward to show that $\xi(k)=2(k-\underline{k}) /(\bar{k}-\underline{k})-1$.
} 
for $j=1, \ldots, J$. To make the expressions above shorter we used the abbreviated notation $\hat{c}_{i}(k) \equiv \hat{c}_{i}\left(k ; a^{i}\right)$ and $\hat{\lambda}_{j}(k) \equiv \hat{\lambda}_{j}\left(k ; a^{j}\right)$.

The next step is to generate projections which give us the necessary number of algebraic equations in the unknown parameters.

Orthogonal Collocation Method According to step 5 in section 4 (see equation (18)), the collocation method assigns the residual functions $R_{i}, i=1, \ldots, J$, and $R_{j+J}$, $j=1, \ldots, J$, from $(35)$ and $(36)$ to be equal zero

$$
\begin{aligned}
R_{i}(k ; \mathbf{a}) & =0, \\
R_{j+J}(k ; \tilde{\mathbf{a}}) & =0,
\end{aligned}
$$

at $k$ 's that are the $N$ zeros of $\phi_{N+1}$ for $R_{i}$ and the $M$ zeros of $\phi_{M+1}$ for $R_{j+J}$, respectively.

Galerkin method The Galerkin method produces projections of the above residual functions by the use of the inner product

$$
\begin{aligned}
\left\langle R_{i}(k ; \mathbf{a}), \phi_{u}(k)\right\rangle & \equiv \int_{\underline{k}}^{\bar{k}} R_{i}(k ; \mathbf{a}) \phi_{u}(k) w(k) d k \\
\left\langle R_{j+J}(k ; \tilde{\mathbf{a}}), \phi_{v}(k)\right\rangle & \equiv \int_{\underline{k}}^{\bar{k}} R_{j+J}(k ; \tilde{\mathbf{a}}) \phi_{v}(k) w(k) d k
\end{aligned}
$$

where the weighting function is given by $w(k) \equiv\left(1-\left(2 \frac{k-\underline{k}}{k-\underline{k}}\right)^{2}\right)^{-1 / 2}$ and $i=1, \ldots, J$, $j=1, \ldots, J, u=1, \ldots, M$ and $v=1, \ldots, N$. We use the Gauss-Chebyshev quadrature for numerical computation of the integration. It gives a simple formula for the Galerkin projections

$$
\begin{aligned}
\sum_{k} R_{i}(k ; \mathbf{a}) \phi_{u}(k) & =0, \\
\sum_{k} R_{j+J}(k ; \tilde{\mathbf{a}}) \phi_{v}(k) & =0,
\end{aligned}
$$

with $k$ 's being the zeros of the polynomial $\phi$ of a degree greater than $M+1$ for $R_{i}$ and greater than $N+1$ for $R_{j+J}$, respectively. 
Least Squares Projection Method According to (20), the least squares projection method looks for parameters ã that minimize the sum of weighted residuals,

$$
\sum_{i=1}^{J} \int_{\underline{k}}^{\bar{k}} R_{i}^{2}(k ; \mathbf{a}) w(k) d k+\sum_{j=1}^{J} \int_{\underline{k}}^{\bar{k}} R_{j+J}^{2}(k ; \tilde{\mathbf{a}}) w(k) d k,
$$

where we used the definition of the inner product as in (39)-(40). After approximating the integrals by the Gauss-Chebyshev quadrature, we obtain a minimization problem

$$
\min _{\tilde{\mathbf{a}} \in \mathbb{R}^{J \times N+J \times M}} \sum_{i=1}^{J} \sum_{k} R_{i}^{2}(k ; \mathbf{a})+\sum_{j=1}^{J} \sum_{k} R_{j+J}^{2}(k ; \tilde{\mathbf{a}})
$$

with $k$ 's being the zeros of the polynomial $\phi$ of a degree greater than $M+1$ for $R_{i}$ greater than $N+1$ for $R_{j+J}$, respectively.

Both the collocation and the Galerkin projections provide us with a system of $J \times(N+M)$ nonlinear algebraic equations in $J \times(N+M)$ unknown approximation parameters. The next task is to include the aggregate conditions (30) and (32) into the set of projection conditions. Before that the two aggregate conditions must be approximated by the Newton-Cotes quadrature formulas ${ }^{12}$

$$
\begin{aligned}
S_{1}(\tilde{\mathbf{a}}) & \equiv K-h \sum_{i=1}^{J} \sum_{k}\left[(1+r(K)-\delta) k+w(K) z_{i}-\hat{c}_{i}(k)\right] \hat{\lambda}_{i}(k), \\
S_{2}(\tilde{\mathbf{a}}) & \equiv 1-h \sum_{i=1}^{J} \sum_{k} \hat{\lambda}_{i}(k),
\end{aligned}
$$

where the step of integration is $h$, and $k$ 's are the midpoints of the intervals. Following the discussion at the end of section 4 , in order to keep the number of conditions the same as the number of parameters, we substitute them for two arbitrarily chosen projection conditions.

In case of the least square projection method the number of conditions does not have to be equal to the number of unknown parameters. Thus we add the squared conditions (45)-(46) to the minimization problem (44)

$$
\min _{\tilde{\mathbf{a}} \in \mathbb{R}^{J \times N+J \times M}} \sum_{i=1}^{J} \sum_{k} R_{i}^{2}(k ; \mathbf{a})+\sum_{j=1}^{J} \sum_{k} R_{j+J}^{2}(k ; \tilde{\mathbf{a}})+\sum_{l=1}^{2} S_{l}^{2}(\tilde{\mathbf{a}}) .
$$

\footnotetext{
${ }^{12}$ See Chapter 7 on numerical integration in Judd (1998).
} 


\section{Results}

In this section we numerically solve the economy described in section 2 using the collocation, Galerkin, and least squares projection methods. We perform the standard accuracy checks and compare these methods in terms of the approximated policy functions, aggregate allocations and distribution of assets.

We parameterize the economy in the standard way used in the macroeconomic literature. We assume a utility function $u(c)=\log c$ and a Cobb-Douglas technology $F(K, L)=A K^{\alpha} L^{1-\alpha}$ with $A=1$ and $\alpha=0.34$. We set the discount factor $\beta=0.9$ and the depreciation rate $\delta=0.1$. The shock structure is limited to $J=2$, i.e., two shocks $z_{L}=0$ and $z_{H}=1$, with a transition matrix $Q\left(z_{L}, z_{L}\right)=0.6, Q\left(z_{L}, z_{H}\right)=0.4$ and $Q\left(z_{H}, z_{L}\right)=Q\left(z_{H}, z_{H}\right)=0.5$. This specification of the transition matrix implies that, in the steady state, $44 \%$ of agents realize the high productivity shock and the remaining $56 \%$ have the low productivity shock. Finally, the choice of the approximation domain $k \in[0.001,6.8]$ allows for an endogenous upper bound of the stationary distribution.

For each projection method, we choose a degree of approximation for the consumption policy functions, $n_{C}$, and a degree of approximation for the cumulative distribution functions, $n_{L}$. The latter degree of approximation is higher as the cumulative distribution function exhibits a greater curvature. We report results for three different combinations of $\left(n_{C}, n_{L}\right)$ for each projection method in Table 1 . As the initial guess of the aggregate capital stock we always use $K_{0}=1.2$ which turns out to be $15 \%$ below the equilibrium level (the results are the same if we started above). We used the Newton algorithm for solving systems of nonlinear equations and the Levenberg-Marquardt algorithm for optimizations. In general, the convergence of all projection methods was very good and it took less than five hundred iterations to converge ${ }^{13}$.

Table 1 shows the largest errors associated with the Euler equations (35) and the stationarity conditions on the distribution function (36) for each level of the productivity

\footnotetext{
${ }^{13}$ We have found that the equilibrium of the discretized economy does not exist in a purely mathematical sense and thus the implied equilibrium conditions can be taken only as an approximation of the continuous economy. Actually, the convergence performance of all three projections methods has been negatively influenced by the properties of such equilibria. However, we still consider such computations worth of the effort and document them as reasonably good approximations.
} 
shock. The Gallerkin and OLS methods performs better than the collocation method. Except for the latter method, the errors generally decline as we increase the degree of approximation. We consider the results from the Galerkin projection method with the seventh- and twelfth-degree approximation for consumption and distribution functions, respectively, as our best approximation. The errors are relatively small with respect to the complexity of the problem: the approximation implies that agents make at most a $\$ 3.90$ mistake for every $\$ 1,000$ they spend.

In Figure 1 we compare our reference Galerkin projection method to an "exact" solution of the stationary competitive equilibrium computed over 800 equally spaced grid points of the capital stock. ${ }^{14}$ In the top panel, we plot in solid lines the approximated consumption policy functions, $c_{H}$ and $c_{L}$, and in the bottom panel, we show the approximated cumulative distribution functions, $\lambda_{H}$ and $\lambda_{L}$. Compared with the exact solutions in dashed lines, the overall fit of the consumption policies is excellent. ${ }^{15}$ The fit of the distribution functions is a little bit worse but what is important, the approximated distribution functions are able to replicate the convex part at low levels of capital, the inflection point as well as the concave part of the distribution functions at higher capital levels.

Since a majority of agents live below the inflection point, the fit at the low levels of capital stock is what matters the most for the stationary recursive competitive equilibrium. Indeed, the approximated aggregated capital stock matches very well the exact level (with an error equal to $0.16 \%$ ). The equilibrium prices are correspondingly close.

\section{Conclusions}

In this paper we have developed a general methodology how to use the projection methods for computing stationary recursive equilibria with heterogeneous agents. We have focused on a general description and a standard example that, we hope, illustrate the applicability of this approach to a wide range of interesting economic problems for which the existing methods cannot be used at the current (and future) state of computer technology.

\footnotetext{
${ }^{14}$ Adding more grid points does not change the policy functions nor the stationary distribution.

${ }^{15}$ Our results are very good especially at the lower levels of capital stock. For a comparison, see Judd (1998), Chapter 11, or McGrattan (1999).
} 
We have not dealt with several issues that are potentially very important: aggregate shocks and out-of-steady-state allocations. Adaptation of our projection method to the case of continuous shocks seems to have rather serious implications for the macroeconomic models with heterogeneous models in general. These topics are left for future research.

Finally, the functional approach developed in this paper can be used to study models in which the distribution of agents is a part of a government's optimization problem. In other words, we believe that this method can be used to compute equilibria in economies with heterogeneous agents in which the distribution of wealth and income is an endogenous policy choice. 


\section{References}

Aiyagari, R. S. (1994). Uninsured idiosyncratic risk and aggregate savings. Quarterly Journal of Economics 109(3), 659-684.

Alvarez, F. and M. Veracierto (1999). Labor market policies in an equilibrium search model. NBER Macroeconomic Annual (14), 265-304.

Atkeson, A. and R. E. Lucas, Jr. (1995). Efficiency and equality in a simple model of efficient unemployment insurance. Journal of Economic Theory 66, 64-98.

Bohacek, R. (2002). Financial intermediation and entrepreneurial activity. CERGE-EI Working Paper Series.

Hansen, G. D. and A. Imrohoroglu (1992). The role of unemployment insurance in an economy with liquidity constraint and moral hazard. Journal of Political Economy 100(1), 118-142.

Huggett, M. (1993). The risk-free rate in heterogeneous-agent incomplete-insurance economies. Journal of Economic Dynamics and Control 17, 953-969.

Huggett, M. (1997). The one-sector growth model with idiosyncratic shocks: Steady states and dynamics. Journal of Monetary Economics 39, 385-403.

Huggett, M. and G. Ventura (1999). On the distributional effects of social security reform. Review of Economic Dynamics 2, 498-531.

Judd, K. L. (1992). Projection methods for solving aggregate growth models. Journal of Economic Theory 58, 410-452.

Judd, K. L. (1998). Numerical Methods in Economics. Cambridge, MA: MIT Press.

Judd, K. L., F. Kubler, and K. Schmedders (2000). Computatinal methods for dynamic equilibria with heterogeneous agents. Mimeo.

Kejak, M. (2000). Minimum weighted residual methods in endogenous growth models. CERGE-EI Working Paper (155).

Krusell, P., V. Quadrini, and J.-V. Rios-Rull (1997). Politico-economic equilibrium and economic growth. Journal of Economic Dynamics and Control 21, 243-272.

Lucas, Jr., R. E. (1980). Equilibrium in a pure currency economy. Economic Inquiry 43, 203-220.

McGrattan, E. R. (1999). Application of weighted residual methods to dynamic economic models. In R. Marimon and A. Scott (Eds.), Computational Methods for the Study of Dynamic Economies, Oxford. Oxford University Press.

Phelan, C. and R. M. Townsend (1991). Computing multi-period, information-constrained optima. Review of Economic Studies 58, 853-881.

Rios-Rull, J. V. (1995). Models with heterogeneous agents. In T. F. Cooley (Ed.), Frontiers of Business Cycle Research, pp. 98-125. Princeton, NJ: Princeton University Press.

Rios-Rull, J.-V. (1997). Computation of equilibria in heterogeneous agent models. Federal Reserve Bank of Minneapolis Staff Report (231). 
Stokey, N. L., R. E. Lucas, Jr., and E. C. Prescott (1989). Recursive Methods in Economic Dynamics. Cambridge, MA: Harvard University Press.

Ventura, G. (1999). Flat tax reform: A quantitative exploration. Journal of Economic Dynamics and Control 23, 1425-1458. 


\begin{tabular}{lcccc}
\hline \hline \multicolumn{3}{c}{ Euler and Stationary Distribution Equation Errors } \\
\hline \hline Degree of & & \multicolumn{3}{c}{ Projection Method } \\
\cline { 3 - 5 } Approximation & Function & Collocation & Galerkin & OLS \\
\hline \hline \multirow{2}{*}{$n_{C}=5$} & $c_{L}$ & 0.0080 & 0.0125 & 0.0070 \\
$n_{L}=7$ & $c_{H}$ & 0.0252 & 0.0129 & 0.0072 \\
& $\lambda_{L}$ & 0.0028 & 0.0039 & 0.0025 \\
& $\lambda_{H}$ & 0.0033 & 0.0023 & 0.0025 \\
$n_{C}=5$ & $c_{L}$ & 0.0127 & 0.0291 & 0.0088 \\
$n_{L}=10$ & $c_{H}$ & 0.0402 & 0.0056 & 0.0065 \\
& $\lambda_{L}$ & 0.0158 & 0.0025 & 0.0019 \\
& $\lambda_{H}$ & 0.0212 & 0.0023 & 0.0019 \\
$n_{C}=7$ & $c_{L}$ & 0.0039 & 0.0024 & 0.0024 \\
$n_{L}=12$ & $c_{H}$ & 0.0072 & 0.0039 & 0.0053 \\
& $\lambda_{L}$ & 0.0084 & 0.0029 & 0.0023 \\
\hline \hline
\end{tabular}

Table 1: Euler and Stationary Distribution Equation Errors. 

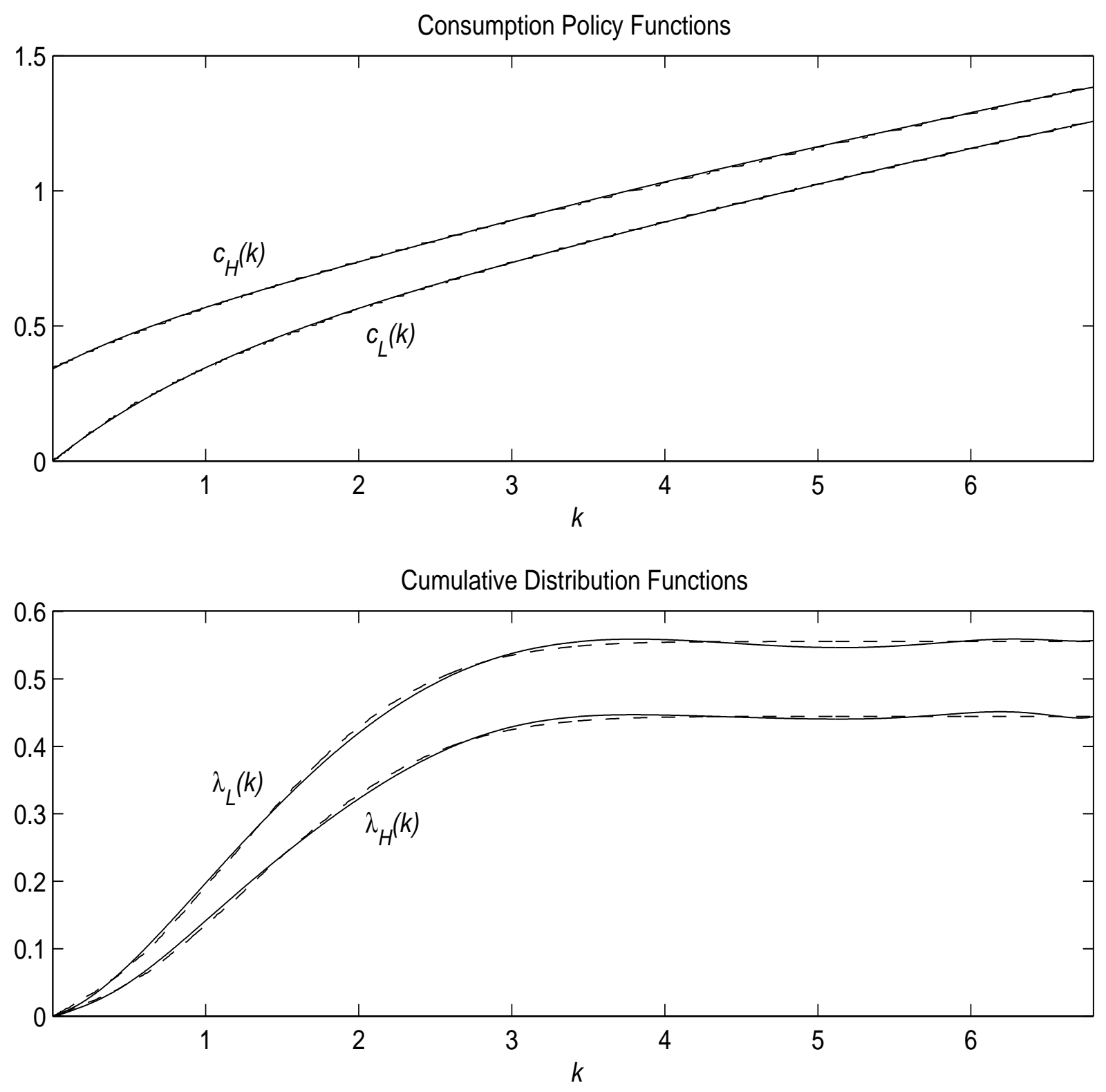

Notes: Exact solution using grid points (dashed lines) and approximation by the Galerkin Projection Method with $n_{C}=7$ and $n_{L}=12$ (solid lines).

Figure 1: Consumption Policy and Cumulative Distribution Functions. 
Individual researchers, as well as the on-line and printed versions of the CERGE-EI Working Papers (including their dissemination) were supported from the following institutional grants:

- Economic Aspects of EU and EMU Entry [Ekonomické aspekty vstupu do Evropské unie a Evropské měnové unie], No. AVOZ70850503, (2005-2010);

- Economic Impact of European Integration on the Czech Republic [Ekonomické dopady evropské integrace na ČR], No. MSM0021620846, (2005-2011);

Specific research support and/or other grants the researchers/publications benefited from are acknowledged at the beginning of the Paper.

(c) Radim Boháček, Michal Kejak, 2005

All rights reserved. No part of this publication may be reproduced, stored in a retrieval system or transmitted in any form or by any means, electronic, mechanical or photocopying, recording, or otherwise without the prior permission of the publisher.

Published by

Charles University in Prague, Center for Economic Research and Graduate Education (CERGE) and

Economics Institute (EI), Academy of Sciences of the Czech Republic

CERGE-El, Politických vězñu 7, 11121 Prague 1, tel.: +420 224005 153, Czech Republic.

Printed by CERGE-EI, Prague

Subscription: CERGE-El homepage: http://www.cerge-ei.cz

Editors: Directors of CERGE and EI

Managing editors: Deputy Directors for Research of CERGE and EI

ISSN 1211-3298

ISBN 80-7343-052-5 (Univerzita Karlova v Praze, CERGE)

ISBN 80-7344-041-5 (Národohospodářský ústav AV ČR, Praha) 
CERGE-EI

P.O.BOX 882

Politických vězňů 7

11121 Praha 1

Czech Republic http://www.cerge-ei.cz 